\title{
PENGARUH GOOD CORPORATE GOVERNANCE DAN VOLUNTARY DISCLOSURE TERHADAP BIAYA HUTANG (COST OF DEBT) PADA PERUSAHAAN PERBANKAN YANG TERDAFTAR DI BURSA EFEK INDONESIA
}

\author{
Akhmad Samhudi \\ Email : Akhmadsamhudiuniska@gmail.com \\ Fakultas Ekonomi Universitas Islam Kalimantan MAB Banjarmasin
}

\begin{abstract}
This research aims to examines variables influencing cost of debt in banking companies listed in Indonesian Stock Exchange. Independent variables are Good Corporate Governance (independent commissioner, managerial ownership, institutional ownership, and audit quality) and voluntary disclosure.

There are 19 banking companies which taken as samples during period 2013 to 2015. Analysis method in this research is multiple regression analysis which used SPSS program 16.0 version. Simultaneously testing used F-test and partially testing used ttest.

The result shows that partially, independent variables which significantly influencing cost of debt are audit quality and voluntary disclosure with each significant value 0.003 and 0.049 (less than 0.05). Simultaneously, independent commissioner, managerial ownership, institutional ownership, audit quality and voluntary disclosure significantly influencing cost of debt in banking companies listed in Indonesia Stock Exchange with significant value 0.000 (below from 0.05 ). Adjusted $\mathrm{R}^{2}$ value 0,305 shows that $30,5 \%$ variation of companies cost of debt can be explained by independent commissioner, managerial ownership, institutional ownership, audit quality and voluntary disclosure and the explained by variables which not used in this research.
\end{abstract}

Keywords: Good Corporate Governance, Voluntary Disclosure, Cost of Debt.

\section{PENDAHULUAN}

Sistem corporate governance yang baik (good corporate governance) memberikan perlindungan efektif kepada para pemegang saham dan pihak kreditur, sehingga mereka bisa meyakinkan diri akan perolehan kembali investasinya dengan wajar dan bernilai tinggi. Penerapan Good Corporate Governance (GCG) diharapkan meningkatkan pengawasan terhadap manajemen untuk mendorong pengambilan keputusan yang efektif, mencegah tindakan oportunistik yang tidak sejalan dengan kepentingan perusahaan, dan mengurangi asimetri 
informasi antara pihak eksekutif dan para stakeholder perusahaan.

Penelitian Juniarti

membuktikan bahwa secara parsial kepemilikan institusional dan kualitas audit berpengaruh signifikan terhadap biaya hutang (cost of debt). Proporsi komisaris independen, kepemilikan manajerial, voluntary disclosure dan variabel control (Debt Equity Ratio dan ukuran perusahaan) tidak berpengaruh signifikan terhadap biaya hutang, sedangkan secara simultan, komisaris independen, kepemilikan manajerial, kepemilika institusional, kualitas audit, dan voluntary disclosure dan variabel control (Debt Equity Ratio dan ukuran perusahaan) secara bersama-sama berpengaruh signifikan terhadap biaya hutang.

Berdasarkan penelitian di atas, peneliti termotivasi untuk melakukan penelitian dengan menggunakan variabel good corporate governance (diproksi dengan komisaris independen, kepemilikan manajerial, kepemilikan institusional, dan kualitas audit), voluntary disclosure dan biaya hutang (cost of debt). Perbedaan penelitian ini dengan penelitian sebelumnya meneliti perusahaan manufaktor dalam terdaftar di BEI dengan periode pengamatan 5 (lima) tahun, sedangkan dalam penelitian ini meneliti perusahaan perbankan yang terdaftar di BEI dengan periode pengamatan 3 (tiga) tahun, agar dapat dibuktikan apakah akan diperoleh hasil yang sama selama 3 (tiga) tahun yakni tahun 2013, 2014, dan 2015.

Tujuan dari penelitian ini adalah untuk mengetahui apakah terdapat pengaruh secara parsial maupun simultan antara good corporate governance (GCG) dan voluntary disclosure terhadap biaya hutang (cost of debt) pada Perusahaan Perbankan yang terdaftar di BEI.

\section{METODE PENELITIAN}

Penelitian ini merupakan penelitian kuantitatif, apabila diliihat dari bentuk data yang diambil. Apabila dilihat dari tingkat eksplanasinya, penelitian ini merupakan penelitian asosiatif, yaitu suatu penelitian yang mencoba mencri hubungan antara variabel independen dengan variabel dependen, yaitu untuk mengetahui pengarh good corporate governance dan voluntary disclosure terhadap biaya hutang (cost of debt) pada Perusahaan 
Perbankan yang terdaftar di Bursa Efek Indonesia (BEI).

Objek dalam penelitian ini adalah Perusahaan Perbankan yang terdaftar di Bursa Efek Indonesia dalam periode pengamatan 3 (tiga) tahun terakhir yaitu tahun 2013, 2014 dan 2015.

\section{Populasi dan Sampel}

Populasi dalam penelitian ini adalah seluruh perusahaan perbankan yang listing di Bursa Efek Indonesia
(BEI) tahun 2013, 2014 dan 2015. Jumlah populasi adalah 29 perusahaan, berdasarkan populasi tersebut ditentukan sampel yang diplilih untuk penelitian ini.

Teknik pemilihan sampel yang digunakan adalah purposive sampling, dengan kriteria sebagai berikut :

Tabel 1

Prosedur Seleksi Sampel

\begin{tabular}{|c|c|}
\hline Kriteria & Jumlah \\
\hline $\begin{array}{l}\text { Perusahaan perbankan yang terdaftar di Bursa } \text { Efek } \\
\text { Indonesia Tahun } 2013,2014 \text { dan } 2015 .\end{array}$ & 29 \\
\hline $\begin{array}{l}\text { Tidak dipilih menjadi sampel karena: } \\
\text { 1. Perusahaan tidak terdaftar selama periode } 2013 \text { s.d } 2015 \\
\text { 2. Laporan tahunan dan laporan keuangan tahunan } \\
\text { perusahaan per } 31 \text { Desember tahun } 2013 \text { s.d } 2015 \text { tidak } \\
\text { tersedia secara berturut-turut di Bursa Efek Indonesia atau } \\
\text { situs resmi perusahaan. }\end{array}$ & 3 \\
\hline Jumlah perusahaan yang tidak memenuhi kriteria & 10 \\
\hline Jumlah perusahaan yang memenuhi kriteria & 19 \\
\hline Jumlah pengamatan untuk setiap sampel & 3 \\
\hline Jumlah pengamatan untuk seluruh sampel & 57 \\
\hline
\end{tabular}

Prosedur seleksi sampel yang menetapkan kriteria bahwa perusahaan yang memiliki total ekuitas negatif tidak dipilih menjadi sampel karena hal ini dapat 
membuat analisis menjadi kurang baik. Perusahaan yang memenuhi kriteria untuk dijadikan sampel sebagai berikut .

\section{Tabel 2}

\section{Daftar Perusahaan Perbankan yang Dijadikan Sampel Penelitian}

\begin{tabular}{|c|c|c|}
\hline No. & Kode Perusahaan & Nama Perusahaan \\
\hline 1. & INPC & PT. Bank Artha Graha Internasional Tbk. \\
\hline 2. & BNBA & PT. Bank Bumi Arta Tbk \\
\hline 3. & BABP & PT. Bank ICB Bumiputera Tbk \\
\hline 4. & BACA & PT. Bank Capital Indonesia Tbk \\
\hline 5. & BBCA & PT. Bank Central Asia Tbk \\
\hline 6. & BNGA & PT. Bank CIMB Niagara Tbk \\
\hline 7. & BDMN & PT. Bank Danamon Indonesia Tbk \\
\hline 8. & BNII & Bank Internasional Indonesia Tbk \\
\hline 9. & BKSW & PT. Bank Kesawan Tbk \\
\hline 10. & BMRI & PT. Bank Mandiri (Persero) Tbk \\
\hline 11 & MAYA & PT. Bank Mayapada Internasional Tbk \\
\hline 12 & MEGA & PT. Bank Mega Tbk \\
\hline 13 & BBNI & PT. Bank Negara Indonesia (Persero) Tbk \\
\hline 14 & NISP & PT. Bank OCBC NISP Tbk \\
\hline 15 & PNBN & PT. Bank Pan Indonesia Tbk \\
\hline 16 & BNLI & PT. Bank Permata Tbk \\
\hline 17 & BBRI & PT. Bank Rakyat Indonesia (Persero) Tbk \\
\hline 18. & BVIC & PT. Victoria Internasional Tbk \\
\hline 19. & MCOR & PT. Bank Windu Ketjana Internasional Tbk \\
\hline
\end{tabular}

Penelitian ini menggunakan laporan keuangan tahunan dan laporan tahunan perusahaan tahun 2013, 2014 dan 2015. Dipilihnya periode pengamatan selama 3(tiga) tahun ini agar menyelaraskan kriteria voluntary disclosure karena adanya perbedaan kriteria antara sebelum dan sesudah adanya kebijakan baru. 


\section{PEMBAHASAN}

1. Pengaruh Komisaris Independen Terhadap Biaya Hutang (Cost of Debt)

Pengujian terhadap hipotesis pertama $\left(\mathrm{H}_{1}\right)$ dengan menggunakan Uji t, menghasilkan nilai signifikansi 0,560 (lebih dari 0,05) yang berarti bahwa $\mathrm{H}_{1}$ ditolak. Hasil ini menunjukkan bahwa variabel komisaris independen tidak berpengaruh secara signifikan terhadap biaya hutang perusahaan perbankan yang terdaftar di Bursa Efek Indonesia. Koefisien regresi komisaris independen sebesar 0.075 menunjukkan hubungan yang negatif/berlawanan dengan biaya hutang. Artinya bahwa setiap penambahan komisaris independen sebesar $1 \%$ maka biaya hutang akan menurun sebesar $0,075 \%$.

\section{Pengaruh}

Kepemilikan

\section{Manajerial Terhadap Biaya Hutang (Cost of Debt)}

Pengujian terhadap hipotesis kedua $\left(\mathrm{H}_{2}\right)$ dengan menggunakan Uji t, menghasilkan nilai signifikansi 0,179 (lebih dari 0,05) yang berarti bahwa $\mathrm{H}_{2}$ ditolak. Hasil ini menunjukkan bahwa variabel kepemilikan manajerial tidak berpengaruh secara signifikan terhadap biaya hutang perusahaan perbankan yang terdaftar di Bursa Efek Indonesia. Koefisien refresi dari kepemilikan manajerial mempunyai nilai negatif sebesar 0,034 yang menunjukkan hubungan yang berlawanan/tidak searah dengan biaya hutang Artinya kepemilikan manajerial meningkat $1 \%$, maka biaya hutang akan berkurang $0,034 \%$.

3. Pengaruh

Kepemilikan Institusional Terhadap Biaya Hutang (Cost of Debt)

Pengujian terhadap hipotesis ketiga $\left(\mathrm{H}_{3}\right)$ dengan menggunakan Uji t, menghasilkan nilai signifikansi 0,685 (lebih dari 0,05) yang berarti bahwa $\mathrm{H}_{3}$ ditolak. Hasil ini menunjukkan bahwa variabel kepemilikan institusional tidak berpengaruh secara signifikan terhadap biaya hutang perusahaan perbankan yang terdaftar di Bursa Efek Indonesia. Koefisien regresi kepemilikan institusional sebesar 0,056 menunjukkan hubungan yang 
positif/searah yaitu bahwa setiap penambahan kepemilikan institusional sebesar $1 \%$, maka akan meningkatkan biaya hutang sebesar $0,056 \%$.

\section{Pengaruh Kualitas Audit} Terhadap Biaya Hutang (Cost of Debt)

Pengujian terhadap hipotesis keempat $\left(\mathrm{H}_{4}\right)$ dengan menggunakan Uji t, menghasilkan nilai signifikansi 0,003 (kurang dari 0,05) yang berarti bahwa $\mathrm{H}_{4}$ diterima. Hasil ini menunjukkan bahwa variabel kualitas audit berpengaruh secara signifikan terhadap biaya hutang perusahaan perbankan yang terdaftar di Bursa Efek Indonesia. Koefisien regresi kualitas audit sebesar -0,208 menunjukkan hubungan yang berlawanan bahwa dengan audit yang dilakukan oleh KAP bigfour, maka akan menurunkan biaya hutang sebesar $0,208 \%$. Artinya semakin baik kualitas audit maka biaya hutang akan menurun.

\section{Pengaruh Voluntary Disclosure Terhadap Cost of Debt}

Pengujian terhadap hipotesis kelima (H5) dengan menggunakan Uji t, menghasilkan nilai signifikansi 0,049 (kurang dari 0,05) yang berarti bahwa H5 diterima. Hasil ini menunjukkan bahwa variabel Voluntary Disclosure berpengaruh secara signifikan terhadap biaya hutang perusahaan perbankan yang terdaftar di Bursa efek Indonesia. Koefisien regresi voluntary disclosure sebesar -0,255 menunjukkan arah hubungan yang berlawanan/negatif, bahwa setiap penambahan $1 \%$ voluntaru disclosure, maka akan menurunkan biaya hutang sebesar $0.255 \%$. artinya jika voluntary disclosure meningkat atau semakin banyak diungkapkannya informasi maka biaya hutang akan berkurang.

\section{KESIMPULAN \\ Komisaris Independen tidak berpengaruh signifikan terhadap besarnya biaya hutang (cost of debt) perusahaan perbankan. Arah hubungan yang ditunjukkan adalah negatif/berlawanan. Artinya bahwa}


Volume 3 Nomor 2, Oktober 2017

setiap penambahan komisaris independen maka biaya hutang akan menurun, karena nasabah dan investor memiliki pandangan terhadap perusahaan adalah baik yang berimbas pada besarnya biaya hutang yang ditanggung perusahaan.

Kepemilikan manajerial tidak berpengaruh signifikan terhadap besarnya biaya hutang perusahaan. Arah hubungan yang ditunjukkan adalah negatif yang artinya dengan bertambahnya kepemilikan manajerial akan mengurangi besarnya biaya hutang, karena pihak manajerial dapat ikut menentukan kebijakan hutang yang diambil perusahaan.

Kepemilikan institusional tidak berpengaruh signifikan terhadap besarnya biaya hutang perusahaan. Arah hubungan yang ditunjukkan adalah positif/searah yang artinya dengan bertambahnya kepemilikan institusional akan meningkatkan biaya hutang. Semakin besar tingkat kepemilikan saham oleh istitusi, maka semakin efektif pula mekanisme kontrol terhadap kinerha manajemen, yang tentu saja akan menarik perhatian dan kepercayaan masyarakat sehingga aktivitas penghimpunan dana perusahaan akan mendorong peningkatan biaya hutang perusahaan.

Kualitas audit berpengaruh secara signifikan terhadap biaya hutang yang ditanggung perusahaan. Arah hubungan yang ditunjukkan adalah negatif, yang berarti penggunaan KAP big-four akan menghasilkan audit yang lebih berkualitas yang dapat secara cermat menentukan biaya hutang yang sebenarnya ditanggung perusahaan.

$$
\text { Voluntary disclosure }
$$

berpengaruh secara signifikan terhadap biaya hutang yang ditanggung perusahaan. Arah hubungan yang ditunjukkan adalah negatif, yang berarti voluntary disclosure yang diungkapkan perusahaan akan mendorong penurunan biaya hutang perusahaan.

\section{DAFTAR PUSTAKA}

Bambang Riyanto. 2001. Dasar-dasar Pembelanjaan Perusahaan. BPFE. Yogyakarta.

Dian Ariny. 2010. Pengaruh Likuiditas, Leverage, Profitabilitas dan Ukuran Perusahaan Terhadap Luas Pengungkapan Sukarela Laporan Keuangan Tahunan Perusahaan Makanan dan Minuman yang Terdaftar di Bursa Efek Indonesia. Skripsi. UNLAM. Banjarmasin. 
Dwi Prastowo./ 2008. Analisis Laporan Keuangan (Konsep dan Aplikasi) Edisi Kedua. UPP STIM YKPN. Yogyakarta.

Dyckman, Thomas R., Dukes, Roland E., \& Davis, Charles J. 2001. Akuntansi Intermediate. Edisi Ketiga Jilid 2. Erlangga. Jakarta.

Fitri Wulansari. 2008. Analisis FaktorFaktor yang Mempengaruhi Pengungkapan Sukarela dalam Laporan Tahunan. UII. Yogyakarta.

Forum for Corporate Governance in Indonesia (FCGI). 2006. Peranan Dewan Komisaris dan Komite Audit dalam Pelaksanaan Corporate Governance (Tata Kelola Perusahaan) Corporate Governance. FCGI. Jakarta.

essence of Good Corporate Governance (konsep dan implementasi perusahaan public dan korporasi Indonesia). Yayasan Pendidikan Pasar Modal Indonesia \& Sinergy Communication. Jakarta.

Gideon S.B. Boediono. 2005. Kualitas Laba: $\quad$ Studi Pengaruh Mekanisme Corporate Governance dan Dampak Manajemen Laba dengan Menggunakan Analisis Jalur. Simposium Nasional Akuntansi VII. Desember 2004. Bali.

Hessel Nogi S. Tangkilisan. 2003. Mengelola Kredit Berbasis Good Corporate Governance. Balairung. Yogyakarta.
Ikatan Akuntan Indonesia. 2009. Standar Akuntansi Keuangan. Salemba Empat. Jakarta.

Imam Ghozali, 2009, Aplikasi Analisis Multivariate dengan Program SPSS. Cetakan IV. Badan Penerbit Universitas Diponegoro. Semarang.

Imam Sjahputra Tunggal \& Amin Widjaja Tunggal. 2002. Memahami Konsep Good Corporate Governance. Harvarindo. Jakarta.

Juniarti \& Agnes Andriyani Sentosa. 2009. Pengaruh Good Corporate Governance, Voluntary Disclosure terhadap Biaya Hutang (Cost of Debt). Jurnal Akuntansi dan Keuangan Universitas Kristen Petra. Vol. 11, No. 2 November 2009. 